\title{
Stability Indicating Liquid Chromatographic Method for Estimation of Trihexyphenidyl Hydrochloride and Risperidone in Tablet Formulation: Development and Validation Consideration
}

\author{
Patel Bhaumik, ${ }^{1}$ Gopani Mehul, ${ }^{1}$ Vikani Kartik, ${ }^{2}$ Patel Rashmin, ${ }^{1}$ and Patel Mrunali ${ }^{3}$ \\ ${ }^{1}$ A. R. College of Pharmacy \& G. H. Patel Institute of Pharmacy, Vallabh Vidyanagar, Anand, Gujarat 388120, India \\ ${ }^{2}$ AUM Research Laboratories, Rakanpur, Gandhinagar 382721, India \\ ${ }^{3}$ Indukaka Ipcowala College of Pharmacy, New Vallabh Vidyanagar, Anand, Gujarat 388121, India \\ Correspondence should be addressed to Patel Rashmin; rbp.arcp@gmail.com
}

Received 11 January 2014; Accepted 13 February 2014; Published 19 March 2014

Academic Editor: Toyohide Takeuchi

Copyright (C) 2014 Patel Bhaumik et al. This is an open access article distributed under the Creative Commons Attribution License, which permits unrestricted use, distribution, and reproduction in any medium, provided the original work is properly cited.

\begin{abstract}
This paper describes validated reverse phase high-performance liquid chromatographic (RP-HPLC) method for simultaneous estimation of trihexyphenidyl hydrochloride (THP) and risperidone (RSP) in the pure powder form and in combined tablet dosage form. The HPLC separation was achieved on a core shell C18 $(100 \mathrm{~mm}$ length $\times 4.6 \mathrm{~mm}, 2.6 \mu \mathrm{m}$ particle size $)$ using methanol : ammonium acetate buffer $1 \%(85: 15 \mathrm{v} / \mathrm{v}$; pH-6.5) as mobile phase and delivered at flow rate of $0.8 \mathrm{~mL} / \mathrm{min}$. The calibration plot showed good linear relationship with $r^{2}=0.997 \pm 0.001$ for THP and $r^{2}=0.998 \pm 0.001$ for RSP in concentration range of 50$175 \mu \mathrm{g} / \mathrm{mL}$ and $50-175 \mu \mathrm{g} / \mathrm{mL}$, respectively. LOD and LOQ were found to be 0.40 and $1.29 \mu \mathrm{g} / \mathrm{mL}$ for THP and 1.24 and $3.92 \mu \mathrm{g} / \mathrm{mL}$ for RSP. Assay of THP and RSP was found to be $100.16 \pm 0.03 \%$ and $99.83 \pm 0.02 \%$, respectively. THP and RSP were subjected to different stress conditions (acidic, basic, oxidative, thermal, and photolytic degradation). The degraded product peaks were well resolved from the pure drug peak. The method was successfully validated as per the ICH guidelines. The developed RP-HPLC method was successfully applied for the estimation of THP and RSP in tablet dosage form.
\end{abstract}

\section{Introduction}

Trihexyphenidyl hydrochloride, chemically known as 1cyclohexyl-1-phenyl-3-(piperidin-1-yl)propan-1-ol, is one of the centrally acting muscarinic antagonists used for the treatment of parkinsonian disorders and drug-induced extrapyramidal movement disorders and as an antispasmodic. Risperidone (RSP), chemically known as 3-\{2-[4-(6-fluoro-1,2benzoxazol-3-yl) piperidin-1-yl] ethyl $\}-2$-methyl- $4 \mathrm{H}, 6 \mathrm{H}, 7 \mathrm{H}$, $8 \mathrm{H}, 9 \mathrm{H}$-pyrido $[1,2-\mathrm{a}]$ pyrimidin-4-one, is benzisoxazole derivative and an atypical antipsychotic drug with high affinity for 5-hydrotryptamine (5-HT) and dopamine D2 receptors. It is used primarily in the management of schizophrenia, inappropriate behaviour in severe dementia, and manic episodes associated with bipolar I disorder. RSP is effective in treating the positive and negative symptoms of schizophrenia owing to its affinity for its "loose" binding affinity for dopamine D2 receptors and additional 5-HT antagonism compared to first generation antipsychotics, which are strong, nonspecific dopamine $\mathrm{D} 2$ receptor antagonists.

Both trihexyphenidyl hydrochloride (THP) and RSP are official in pharmacopoeia. A literature survey revealed that high-performance liquid chromatography (HPLC) for determination of THP and RSP in tablet [1-3] was reported. Further, HPLC method for estimation of RSP in plasma [4], bulk drug and pharmaceutical formulation [5], tablet [6-8], HPLC-MS/MS in plasma [9], and TLC densitometry method $[10,11]$ were reported. However, to the best of our knowledge, no article related to stability indicating method for estimation of THP and RSP in tablet formulation was reported. The present study describes the development and validation of a stability indicating RP-HPLC method for the simultaneous 
quantitative estimation of THP and RSP in pure powder and marketed tablet formulation. The developed method was successfully applied for the routine analysis of THP and RSP in tablet formulation.

\section{Experimental}

2.1. Materials. The pure THP and RSP were gratis from AUM Research Laboratories (Gandhinagar, India). HPLC-grade methanol, water, and ammonium acetate were purchased from E. Merck Ltd. (Mumbai, India).

2.2. Apparatus. The method was developed using UltiMate 3000 HPLC series (Thermo Scientific) equipped with SPD $20 \mathrm{~A}$ detector, isocratic pump system, autoinjector, and core shell C-18 SunShell Technology column $(100 \mathrm{~cm} \times 4.6 \mathrm{~mm}$ id, $2.6 \mu$ particle size).

2.3. Chromatographic Condition. The mobile phase consisted of methanol: ammonium acetate buffer $(\mathrm{pH} \mathrm{6.5)}$ in ratio of $85: 15$ which was filtered through a Nylon $0.45 \mu \mathrm{m}$ membrane filter and degassed before use. The mobile phase was pumped at a flow rate of $0.8 \mathrm{~mL} / \mathrm{min}$. The amount of drug solution injected was $20 \mu \mathrm{L}$. The UV light absorption of analyte in elution was detected at a wavelength of $215 \mathrm{~nm}$.

2.3.1. Preparation of Ammonium Acetate Buffer. Accurately, weighed $38.5 \mathrm{gm}$ of ammonium acetate was transferred into a $500 \mathrm{~mL}$ beaker and dissolved in $400 \mathrm{~mL}$ HPLC grade water. The $\mathrm{pH}$ of the solution was adjusted to 6.5 by dropwise addition of glacial acetic acid. This solution was transferred into a $500 \mathrm{~mL}$ volumetric flask and diluted up to the mark using HPLC-grade water.

2.4. Preparation of THP Standard Stock Solution. An accurately weighed quantity of pure THP $50 \mathrm{mg}$ was transferred into $50 \mathrm{~mL}$ volumetric flask and made up the volume with mobile phase to obtain the final concentration of $1000 \mu \mathrm{g} / \mathrm{mL}$.

2.5. Preparation of RSP Standard Stock Solution. An accurately weighed quantity of pure RSP $50 \mathrm{mg}$ was transferred into $50 \mathrm{~mL}$ volumetric flask and made up the volume with mobile phase to obtain the final concentration of $1000 \mu \mathrm{g} / \mathrm{mL}$.

2.6. Sample Preparation for Determination of THP and RSP in Tablet Formulation. Tablet was powdered and weight equivalent to $25 \mathrm{mg}$ of RSP and $25 \mathrm{mg}$ of THP was transferred into $25 \mathrm{~mL}$ volumetric flask. About $10 \mathrm{~mL}$ of mobile phase was added and sonicated for 10 minutes. The solution was cooled to the room temperature and made up the volume with mobile phase. The solution was filtered through Whatman filter paper (grade 42); filtrate was collected after discarding the first few $\mathrm{mL}$. One $\mathrm{mL}$ of this filtrate was transferred to $10 \mathrm{~mL}$ volumetric flask and diluted to $10 \mathrm{~mL}$ with mobile phase to obtain the final concentration of $100 \mu \mathrm{g} / \mathrm{mL}$ of both of the drugs.

\subsection{Method Validation}

2.7.1. System Suitability Test. The system suitability test was carried out to evaluate the resolution and reproducibility of the system for the analysis to be performed, using sixreplicate injection of a reference solution of THP and RSP. The parameters measured were retention time, number of theoretical plates, and tailing factor.

2.7.2. Specificity. Specificity is the ability of the method to measure the analyte response in the presence of its potential impurities and degradation products. Commonly used formulation excipients were spiked into a preweighed quantity of drugs. The chromatogram was taken by appropriate dilutions and the quantities of drugs were determined [12-16].

2.7.3. Linearity Study. Calibration curves were constructed by plotting peak area versus concentrations [12-16] of THP and RSP, respectively, and regression equations were calculated. The calibration curves were plotted over the five different concentrations in range $50-175 \mu \mathrm{g} / \mathrm{mL}$ of THP and $50-175 \mu \mathrm{g} / \mathrm{mL}$ of RSP.

2.7.4. Precision. Precision of the analytical method was studied by analysis of three replicates of standard solution in three different concentrations. It was demonstrated by repeatability (intraday precision) and intermediate precision (interday precision) of the solutions [12-16].

2.7.5. Detection Limit and Quantitation Limit. The limit of detection (LOD) is the lowest concentration of an analyte that can be reliably differentiated from background levels; limit of quantification (LOQ) of an individual procedure is the lowest amount of analyte that can be quantitatively determined [12$16]$.

2.7.6. Accuracy (\% Recovery). The accuracy of the method was determined by calculating the recovery of THP and RSP by the standard addition method. Three different solutions were prepared with a known addition of pure THP and RSP to give a concentration range of $50 \%-175 \%$ of that in a test preparation.

2.7.7. Robustness. Robustness of the method was studied by changing the temperature, flow rate of mobile phase, and the $\mathrm{pH}$ of mobile phase [12-16].

\section{Forced Degradation Study}

3.1. Acid Hydrolysis. Standards of THP (100 mg) and RSP (100 mg) were accurately weighed and transferred into three sets of $250 \mathrm{~mL}$ round bottom flasks. About $20 \mathrm{~mL}$ of $2 \mathrm{~N} \mathrm{HCl}$ was added to all flasks and refluxed on heated mantle for $45 \mathrm{~min}$ at $80^{\circ} \mathrm{C}$.

3.2. Alkali Hydrolysis. Standards of THP (100 mg) and RSP (100 mg) were accurately weighed and transferred into three 


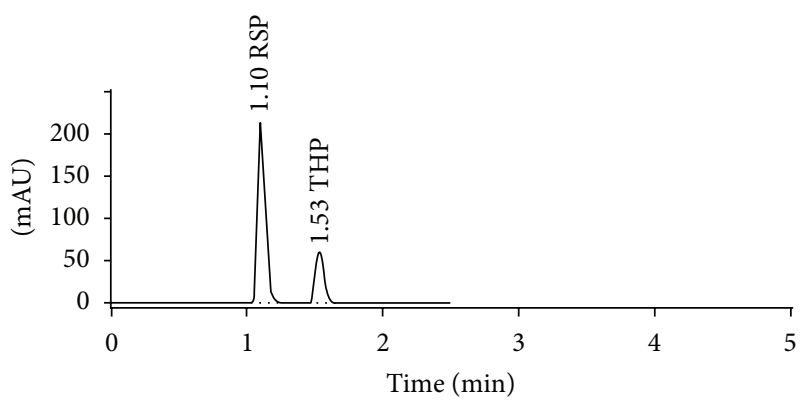

FIGURE 1: Chromatogram of THP and RSP in methanol: ammonium acetate $(85: 15 \mathrm{v} / \mathrm{v}, \mathrm{pH} 6.5)$ at flow rate $0.8 \mathrm{~mL} / \mathrm{min}$, at $215 \mathrm{~nm}$.

sets of $250 \mathrm{~mL}$ round bottom flasks. About $20 \mathrm{~mL}$ of $1 \mathrm{~N} \mathrm{NaOH}$ was added to all flasks and refluxed on heated mantle for $60 \mathrm{~min}$ at $80^{\circ} \mathrm{C}$.

3.3. Oxidative Degradation. Standards of THP (100 mg) and RSP (100 mg) were accurately weighed and transferred into three sets of $250 \mathrm{~mL}$ round bottom flasks. About $20 \mathrm{~mL}$ of $6 \%$ $\mathrm{H}_{2} \mathrm{O}_{2}$ was added to all flasks and refluxed on heated mantle for $2 \mathrm{hr}$ at $80^{\circ} \mathrm{C}$.

3.4. Thermal Degradation. Standard of THP (100 mg) and RSP (100 mg) was accurately weighed and transferred into Petri dish individually and spread into thin layer with spatula; this Petri dish was placed in the hot air oven for 1 hour at $80^{\circ} \mathrm{C}$.

Heated drug samples of THP (100 mg) and RSP (100 mg) were taken into $100 \mathrm{~mL}$ volumetric flask and dissolved in mobile phase. Volume was made up to the mark using mobile phase. $1 \mathrm{~mL}$ of above sample was transferred into $10 \mathrm{~mL}$ volumetric flask and diluted up to the mark using mobile phase. It was filtered through $0.45 \mu$ cellulose acetate filter and filtrate was used for chromatographic analysis.

3.5. Photolytic Degradation. Standard of THP $(100 \mathrm{mg})$ and RSP (100 mg) was accurately weighed and transferred into Petri dish individually and spread into thin layer with spatula; this Petri dish was put inside the UV Chamber for 1 hour.

UV-exposed drugs samples of THP (100 mg) and RSP $(100 \mathrm{mg})$ were taken into $100 \mathrm{~mL}$ volumetric flask, and dissolved in mobile phase. Volume was made up to the mark using mobile. $1 \mathrm{~mL}$ of above sample was taken into $10 \mathrm{~mL}$ volumetric flask in a few $\mathrm{mL}$ of mobile phase and sonicated for $10 \mathrm{~min}$; this solution was cooled to the room temperature and made up the volume up to the mark using mobile phase. It was filtered through $0.45 \mu$ cellulose acetate filter and filtrate was used for chromatographic analysis.

\section{Results and Discussion}

4.1. HPLC Method Development and Optimization. To optimize the HPLC parameters, several mobile phase compositions were tried. A satisfactory separation of THP and RSP with good peak symmetry and steady baseline was obtained
TABLE 1: Summary of HPLC method development and validation.

\begin{tabular}{lcc}
\hline \multirow{2}{*}{ Parameters } & \multicolumn{2}{c}{ Data obtained } \\
& RSP & THP \\
\hline Theoretical plate & $3508 \pm 230$ & $2670 \pm 190$ \\
Retention time (min) & $1.10 \pm 0.01$ & $1.53 \pm 0.01$ \\
Correlation coefficient & $0.998 \pm 0.01$ & $0.997 \pm 0.01$ \\
Linearity $(n=6)$ & $50-175(\mu \mathrm{g} / \mathrm{mL})$ & $50-175(\mu \mathrm{g} / \mathrm{mL})$ \\
Precision (\% RSD) & & \\
$\quad$ Intraday & 0.047 & 0.368 \\
$\quad$ Interday & 0.273 & 0.561 \\
Repeatability $(n=6)$ & 0.181 & 0.656 \\
Accuracy (\% recovery) & $99.42-100.26 \%$ & $99.06-100.42 \%$ \\
LOD & $0.40(\mu \mathrm{g} / \mathrm{mL})$ & $1.24(\mu \mathrm{g} / \mathrm{mL})$ \\
LOQ & $1.29(\mu \mathrm{g} / \mathrm{mL})$ & $3.92(\mu \mathrm{g} / \mathrm{mL})$ \\
\hline
\end{tabular}

with the mobile phase composition of methanol: ammonium acetate buffer (85:15 v/v, pH 6.5). Quantitation of analytes was carried out based on peak area obtained with UV detection at $215 \mathrm{~nm}$ wavelength. Complete resolution of the peaks with clear baseline separation was obtained (Figure 1).

4.2. Method Validation. The linearity data described in the present study demonstrate an acceptable linearity for THP and RSP. The calibration plot showed good linear relationship with $r^{2}=0.997 \pm 0.001$ for THP and $r^{2}=0.998 \pm 0.001$ for RSP in concentration range of $50-175 \mu \mathrm{g} / \mathrm{mL}$ and $50-175 \mu \mathrm{g} / \mathrm{mL}$, respectively. The precision, evaluated as the repeatability of the method, was studied by calculating the RSD value. The intermediate precision composed of two parameters: intraday $(n=3)$ and interday $(n=3)$ in which the RSD value for intraday precision for THP was $0.368 \pm 0.112$ and $0.047 \pm$ 0.20 for RSP. In interday precision RSD value for THP was $0.273 \pm 0.130$ and $0.561 \pm 0.212$ for RSP. The RSD value for intermediate precision was found to be $<2 \%$, which indicates that the proposed method is reproducible. The LOD and LOQ were determined from slops of linear regression curves. LOD and LOQ were found to be 0.40 and $1.29 \mu \mathrm{g} / \mathrm{mL}$ for THP and 1.24 and $3.92 \mu \mathrm{g} / \mathrm{mL}$ for RSP. The accuracy was assessed by the recovery experiments that were performed by the standard addition method. The recoveries obtained were 100.22 \pm 0.74 and $99.91 \pm 0.34$ for THP and RSP, respectively. The high value indicates that the method is accurate. Retention time variation was found to be $<1 \%$. Hence, the method was found to be robust for estimation of THP and RSP. Excipients used in the specificity studies did not interfere with the estimation of either of drugs by the proposed method. Hence, the method was found to be specific for estimation of THP and RSP. All the parameters of system suitability come within acceptable range. Results indicate that the system is suitable for the analysis intended (Table 1).

4.3. Method Application. The proposed RP-HPLC method was applied for the determination of THP and RSP in tablet formulation. Assay of THP and RSP was found to be $100.16 \pm$ 0.03 and $99.83 \pm 0.02 \%$, respectively. The results demonstrate 
TABLE 2: Assay results of tablet formulation by RP-HPLC method.

\begin{tabular}{cccccc}
\hline & \multicolumn{2}{c}{ Name of drug } & \multicolumn{2}{c}{ Amount found } & \multicolumn{2}{c}{$\%$ Assay \pm SD $(n=3)$} \\
& RSP & THP & RSP & THP & RSP \\
Tablet & $2 \mathrm{mg}$ & $2 \mathrm{mg}$ & 2.02 & 1.99 & \\
& $2 \mathrm{mg}$ & $2 \mathrm{mg}$ & 1.98 & 2.04 & $99.83 \pm 0.02$ \\
\hline
\end{tabular}

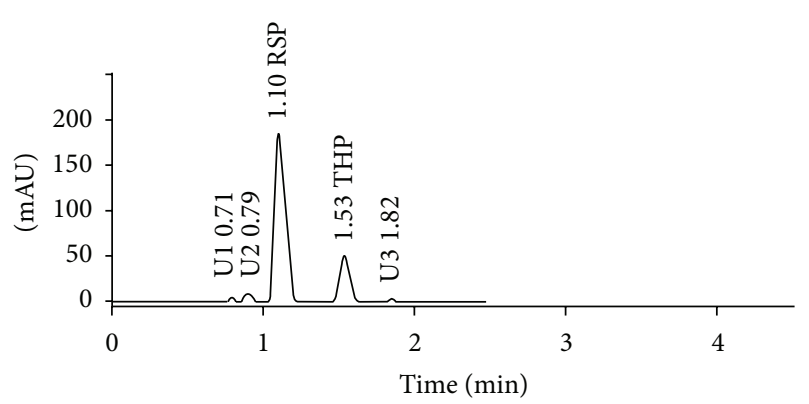

(a)

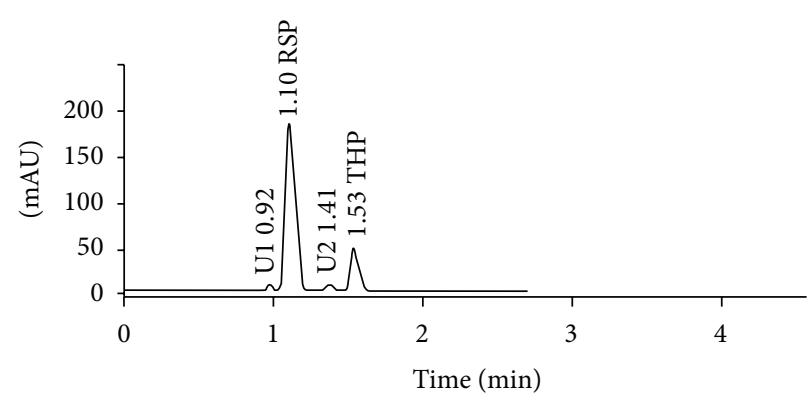

(c)

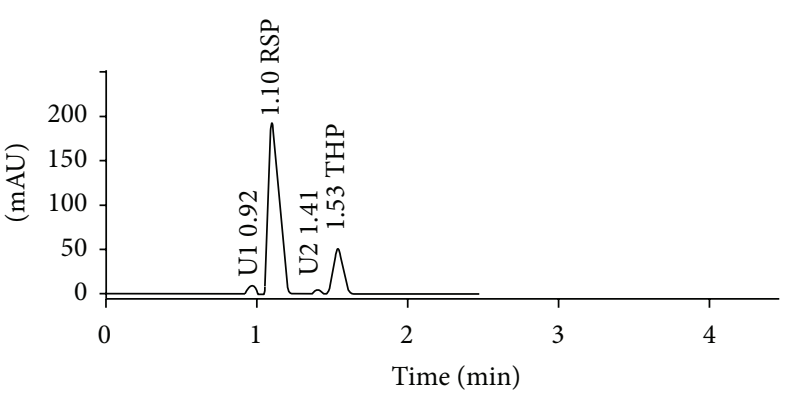

(b)

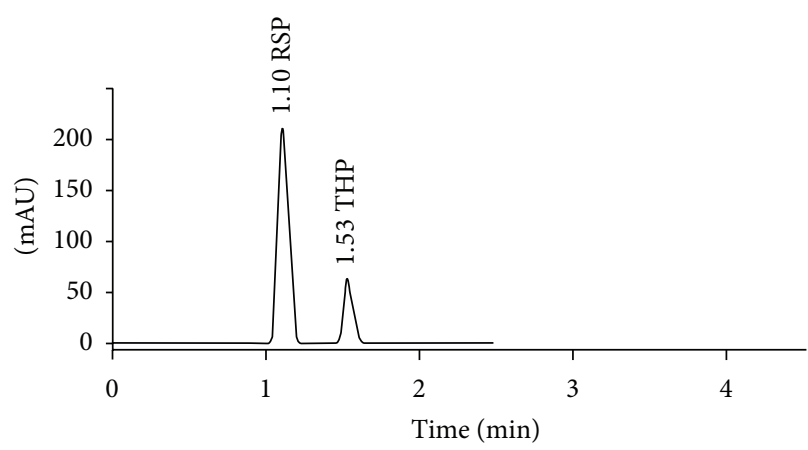

(d)

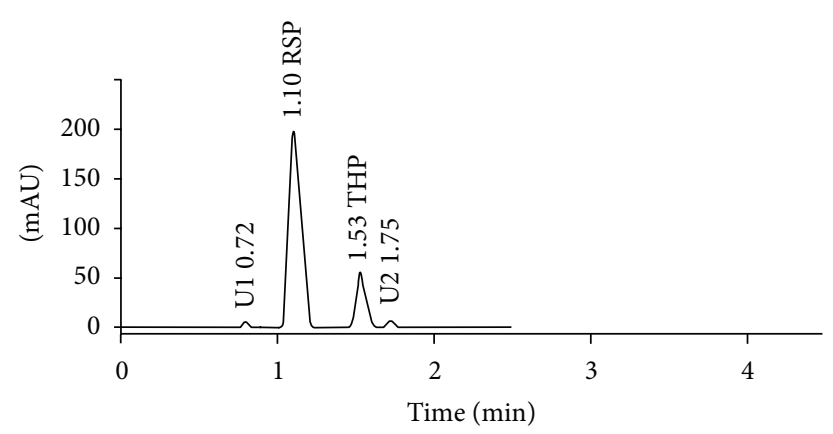

(e)

FIGURE 2: Chromatogram of THP and RSP degradation. (a) Acidic degradation. (b) Basic degradation. (c) Oxidative degradation. (d) Thermal degradation. (e) Photolytic degradation.

the quality of the analyzed pharmaceutical samples and the applicability of the method for QC analysis (Table 2).

4.4. Forced Degradation Study. Forced degradation is performed to provide stability indicating properties of an analytical method. The result from stress testing studies indicated that the method was specific for THP and RSP. Both drugs were found to be unstable for thermal degradation. Chromatograms of mixture drugs after degradation under various force conditions are shown in Figure 2. Percentage of degradation of pure drugs is mentioned in Table 3.

\section{Conclusion}

RP-HPLC method for estimation and quantification of THP and RSP was successfully developed and validated according to the ICH guidelines. The validation results showed that this method was specific, sensitive, linear, precise, accurate, 
TABLE 3: Degradation of THP and RSP at different stress conditions.

\begin{tabular}{|c|c|c|c|c|}
\hline Stress condition/strength/duration & Drugs & Peak area & $\%$ Assay of drug after degradation & \% Degradation \\
\hline \multirow{2}{*}{ Acidic/2 N HCl/45 min } & RSP & 68539 & $79.09 \%$ & $20.90 \%$ \\
\hline & ТHP & 20852 & $82.46 \%$ & $17.53 \%$ \\
\hline \multirow{2}{*}{ Basic/1 N NaOH/60 min } & RSP & 75677 & $87.29 \%$ & $12.70 \%$ \\
\hline & THP & 20710 & $89.79 \%$ & $18.09 \%$ \\
\hline \multirow{2}{*}{ Oxidative $/ 6 \% \mathrm{H}_{2} \mathrm{O}_{2} / 2 \mathrm{hr}$} & RSP & 74820 & $86.33 \%$ & $13.66 \%$ \\
\hline & THP & 19901 & $75.53 \%$ & $24.46 \%$ \\
\hline \multirow{2}{*}{ Thermal/dry heating $/ 80^{\circ} \mathrm{C} / 60 \mathrm{~min}$} & RSP & 86689 & $99.99 \%$ & No degradation \\
\hline & THP & 25286 & $99.99 \%$ & No degradation \\
\hline \multirow{2}{*}{ Photolytic/UV light/60 min } & RSP & 76385 & $91.60 \%$ & $11.88 \%$ \\
\hline & THP & 22528 & $95.02 \%$ & $10.90 \%$ \\
\hline
\end{tabular}

and robust. It can be concluded that there is no other coeluting peak with main peaks and the method is specific for the determination of THP and RSP in combined tablet formulation. So it can be concluded that the developed RPHPLC method can be successfully applied to the combination of THP and RSP in tablet dosage form.

\section{Conflict of Interests}

The authors declare that there is no conflict of interests regarding the publication of this paper.

\section{Acknowledgment}

The authors are grateful to the AUM Research Laboratories, Gandhinagar, India, for carrying out this research work.

\section{References}

[1] S. D. Santhosam and S. Kanan, "An HPLC method for the simultaneous estimation of Risperidone and Trihexyphenidyl hydrochloride from bulk and dosage form," Hygeia Journal for Drug and Medicine, vol. 3, no. 1, pp. 29-33, 2011.

[2] D. Patel and J. Patel, "Development and validation of RPHPLC method for simultaneous estimation of Risperidone and Trihexyphenidyl hydrochloride in tablet dosage forms," International Journal of Pharmaceutical Sciences Review and Research, vol. 4, no. 3, p. 8, 2010.

[3] V. Rajamanickam, D. Santhosam, D. Sridharan, and A. Thenmozhi, "Simultaneous determination of risperidone and Trihexhyphenidyl hydrochloride from bulk and tablet dosage form by RP-HPLC," Asian Journal of Research in Chemistry, vol. 3, no. 3, pp. 549-551, 2010.

[4] M. F. Seyyed, Z. Afshin, S. Alireza, and K. Arash, "Rapid high performance liquid chromatographic determination of risperidone in human plasma," Iranian Journal of Pharmaceutical Research, no. 1, pp. 37-40, 2005.

[5] Z. R. Dedanla, R. R. Dedanla, N. R. Sheth, J. B. Patel, and B. Patel, "Stability indicating HPLC determination of risperidone in bulk drug and pharmaceutical formulation," International Journal of Analytical Chemistry, vol. 2011, Article ID 124917, 6 pages, 2011.

[6] S. Bladania, K. K. Bhatt, R. S. Mehta, and D. A. Shah, "RP-HPLC estimation of risperidone in tablet dosage forms," Indian Journal of Pharmaceutical Sciences, vol. 70, no. 4, pp. 494-497, 2008.
[7] A. P. Suthar, S. A. Dubey, S. R. Patel, and A. M. Shah, "Determination of Risperidone and forced degradation behavior by HPLC in tablet dosage form," International Journal of PharmTech Research, vol. 1, no. 3, pp. 568-574, 2009.

[8] A. Maślanka, J. Krzek, and A. Patrzałek, "Determination of risperidone in tablets in the presence of its degradation products and placebo-derived constituents," Acta Poloniae Pharmaceutica-Drug Research, vol. 66, no. 5, pp. 461-470, 2009.

[9] H. Ming-zhu, S. Jian-zhong, C. Jun-chun, L. Jian, and Z. Huili, "Determination of risperidone in human plasma by HPLCMS/MS and its application to a pharmacokinetic study in Chinese volunteers," Journal of Zhejiang University: Science B, vol. 9, no. 2, pp. 114-120, 2008.

[10] D. G. Rao, S. Kathirvel, and S. V. Satyanarayana, "Development and validation of TLC-densitometry method for the estimation of antipsychotic drug in bulk and tablet formulation," International Journal of ChemTech Research, vol. 2, no. 4, pp. 20632069, 2010

[11] R. B. Patel, M. R. Patel, K. K. Bhatt, and B. G. Patel, "HPTLc method development and validation for analysis of risperidone in formulations, and in-vitro release study," Acta Chromatographica, vol. 22, no. 4, pp. 549-567, 2010.

[12] V. Rajamanickam, D. Santhosam, D. Sridharan, and A. Thenmozhi, "Simultaneous determination of Risperidone and Trihexhyphenidyl Hydrochloride from bulk and tablet dosage form by RP-HPLC," Asian Journal of Research in Chemistry, vol. 3, no. 3, pp. 549-551, 2010.

[13] R. B. Patel, M. R. Patel, K. K. Bhatt, and B. G. Patel, "HPTLC method development and validation: quantification of paliperidone in formulations and in vitro release study," Analytical Methods, vol. 2, no. 5, pp. 525-531, 2010.

[14] M. R. Patel, R. B. Patel, J. R. Parikh, and B. G. Patel, "HPTLC method for estimation of tazarotene in topical gel formulations and in vitro study," Analytical Methods, vol. 2, no. 3, pp. 275-281, 2010.

[15] R. B. Patel, M. R. Patel, N. Dubey, N. N. Dubey, and B. G. Patel, "HPTLC method development and validation: strategy to minimize methodological failures," Journal of Food and Drug Analysis, vol. 20, no. 4, pp. 561-571, 2012.

[16] ICH Harmonised Tripartite Guideline, Validation of Analytical procedures: Text and Methodology, Q2 (R1), Geneva, Switzerland, 2005, http://www.ich.org. 

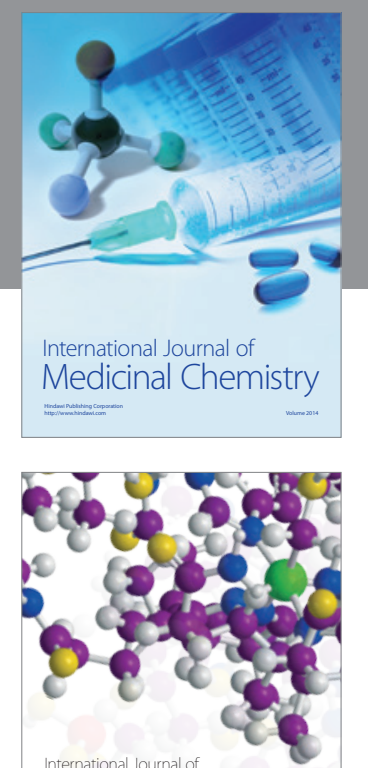

\section{Carbohydrate} Chemistry

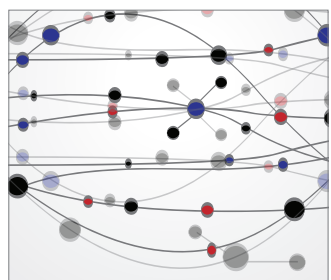

The Scientific World Journal
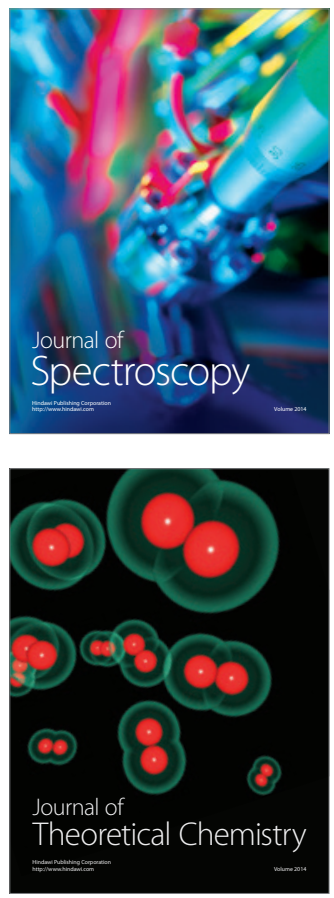
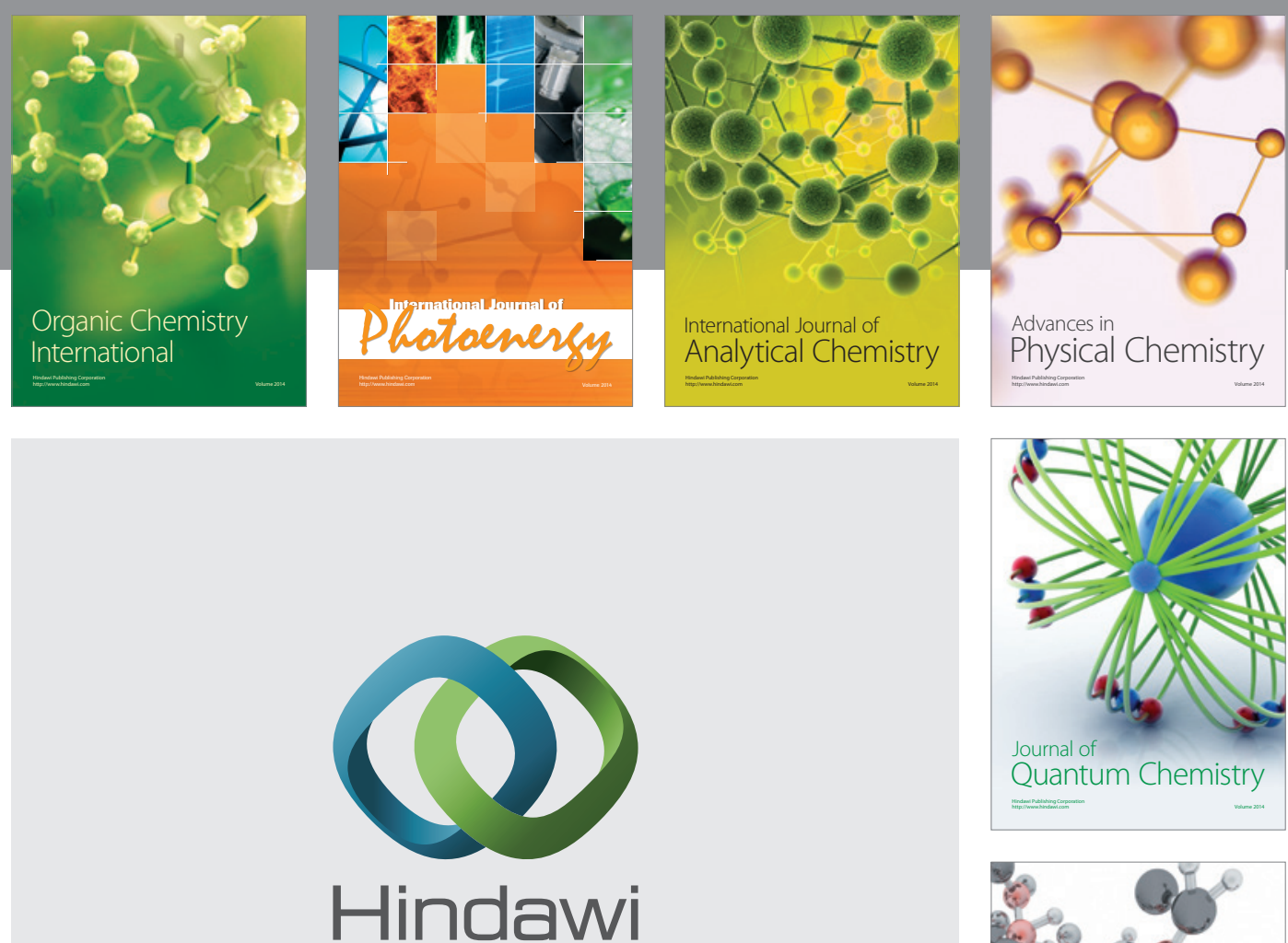

Submit your manuscripts at

http://www.hindawi.com

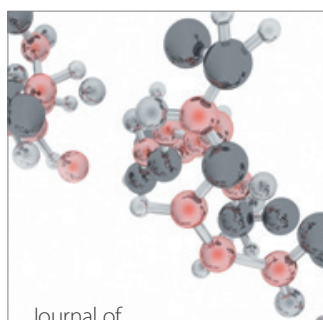

Analytical Methods

in Chemistry

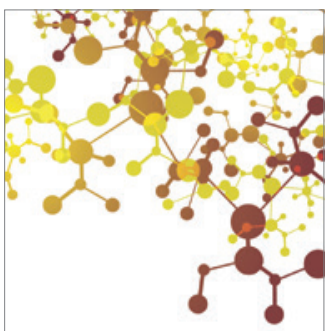

Journal of

Applied Chemistry

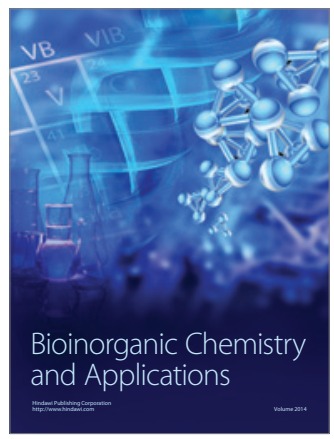

Inorganic Chemistry
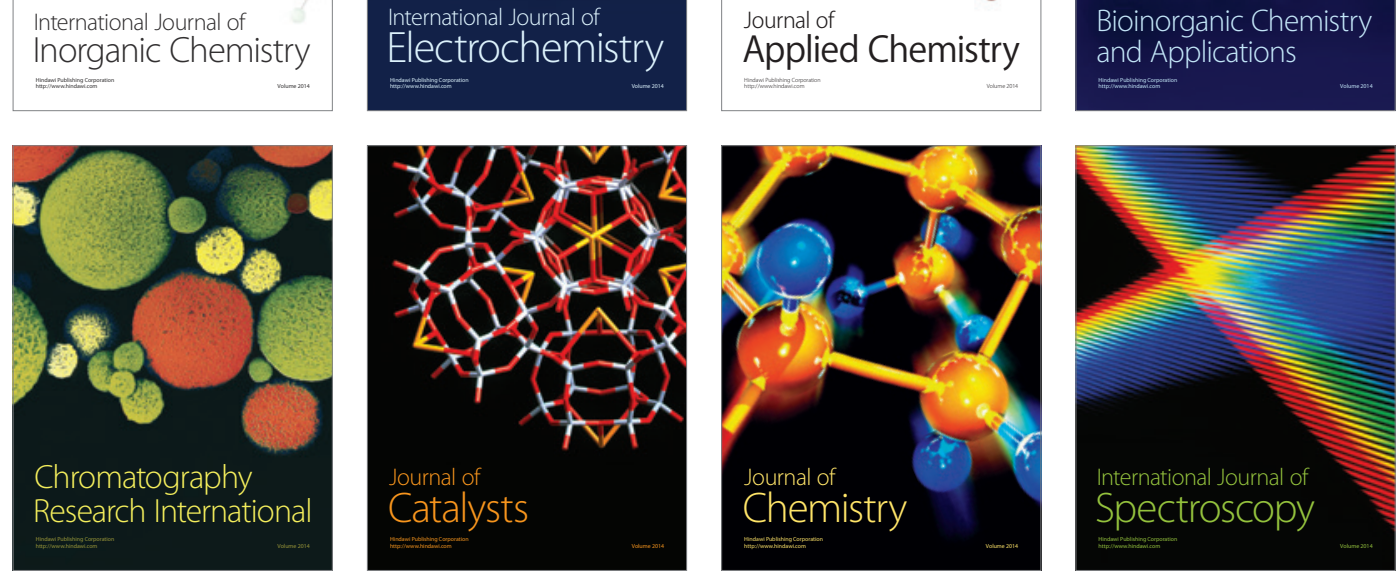